\title{
Comparison of Diagnosis-Specific Survival Scores for Patients with Small-Cell Lung Cancer Irradiated for Brain Metastases
}

\author{
Dirk Rades ${ }^{1}{ }^{*}$, Heinke C. Hansen ${ }^{1}$, Stefan Janssen ${ }^{1,2}$ and Steven E. Schild ${ }^{3}$ \\ 1 Department of Radiation Oncology, University of Lübeck, 23562 Lübeck, Germany; \\ heinke_hansen@web.de (H.C.H.); st-janssen@gmx.net (S.J.) \\ 2 Medical Practice for Radiotherapy and Radiation Oncology, 30161 Hannover, Germany \\ 3 Department of Radiation Oncology, Mayo Clinic, Scottsdale, AZ 85259, USA; sschild@mayo.edu \\ * Correspondence: dirk.rades@uksh.de; Tel.: +49-451-500-45400
}

Received: 28 January 2019; Accepted: 14 February 2019; Published: 16 February 2019

\begin{abstract}
Diagnosis-specific survival scores including a new score developed in 157 patients with brain metastases from small-cell lung cancer (SCLC) receiving whole-brain radiotherapy (WBRT) with 30 Gy in 10 fractions (WBRT-30-SCLC) were compared. Three prognostic groups were designed based on the 6-month survival probabilities of significant or almost significant factors, (age, performance score, number of brain metastases, extra-cerebral metastasis). Six-month survival rates were $6 \%$ (6-11 points), 44\% (12-14 points) and 86\% (16-19 points). The WBRT-30-SCLC was compared to three disease-specific scores for brain metastasis from SCLC, the original and updated diagnosis-specific graded prognostic assessment DS-GPA classifications and the Rades-SCLC. Positive predictive values (PPVs) used to correctly predict death $\leq 6$ months were 94\% (WBRT-30-SCLC), 88\% (original DS-GPA), $88 \%$ (updated DS-GPA) and 100\% (Rades-SCLC). PPVs to predict survival $\geq 6$ months were $86 \%, 75 \%, 76 \%$ and $100 \%$. For WBRT-30-SCLC and Rades-SCLC, differences between poor and intermediate prognoses groups and between intermediate and favorable prognoses groups were significant. For both DS-GPA classifications, only the difference between poor and intermediate prognoses groups was significant. Of these disease-specific tools, Rades-SCLC appeared to be the most accurate in identifying patients dying $\leq 6$ months and patients surviving $\geq 6$ months after irradiation, followed by the new WBRT-30-SCLC and the DS-GPA classifications.
\end{abstract}

Keywords: brain metastasis; small-cell lung cancer; whole-brain radiotherapy; diagnosis-specific survival scores; positive predictive values

\section{Introduction}

Various radiotherapy techniques are available for the treatment of brain metastasis including whole-brain radiotherapy (WBRT), stereotactic radiosurgery (SRS) and fractionated stereotactic radiotherapy (FSRT) [1]. The use of SRS or FSRT alone is generally limited to patients with a maximum of 3-5 intracerebral lesions, particularly in case of less radiosensitive primary tumors such as malignant melanomas and renal cell carcinomas. During recent years these local therapies have even been used for up to 10 lesions [2]. However, despite these new developments, WBRT alone is still considered appropriate for many patients with brain metastases, particularly for patients with more than 3-5 lesions or in case of significant comorbidities or a poor performance status [1]. In comparison to other primary tumors, WBRT is frequently used for brain metastasis from small-cell lung cancer (SCLC), since this tumor tends to spread to the brain, resulting in multiple cerebral lesions. Even if brain metastases are not present, many patients with SCLC receive WBRT as prophylactic cranial irradiation [3]. When a patient with brain metastasis from SCLC receives WBRT, a variety of 
dose-fractionation schedules are available including short-course WBRT with 20 Gy in 5 fractions of 4 Gy and the longer-course schedules such as $30 \mathrm{~Gy}$ in 10 fractions and $40 \mathrm{~Gy}$ in 20 fractions [1].

When selecting the most appropriate schedule for a specific patient, the patient's remaining lifespan should be taken into consideration. Patients with a short lifespan are good candidates for short-course WBRT, spending the least time possible receiving treatment to use the remaining lifetime for other important issues. Short-course WBRT is a reasonable option for these patients, since it is as effective as longer-course schedules in patients with multiple lesions and limited prognoses [4]. Since the risk of neuro-cognitive deficits caused by WBRT increases with lifetime, patients with intermediate or favorable survival prognoses appear to be better treated with lower doses per fraction that were reported to result in less neuro-cognitive decline than higher doses per fraction [5,6]. In addition, the risk of neuro-cognitive deficits can be reduced with the modern technique of hippocampal sparing WBRT and the administration of memantine [7-9]. Patients with very favorable prognoses may additionally benefit from total doses $>30$ Gy in terms of better intracerebral control and survival [10].

Scoring tools for estimating the survival of patients with brain metastasis were created to help physicians choosing the best individual WBRT schedule [11-14]. Such scoring tools included the recursive partitioning analysis (RPA) classification published in 1997 and the graded prognostic assessment (GPA) classification from 2008 [11,12]. Both classifications were designed from heterogeneously treated patient cohorts. Treatments included different WBRT programs, combinations of WBRT and misonidazole or chemotherapy, and in case of the GPA classification also WBRT plus a SRS boost. Thus, hidden selection biases may have been introduced when creating the scoring tools as these were created retrospectively. Therefore, we presented another score in 2008 that was obtained from patients treated with WBRT alone [13]. Additionally, different WBRT schedules were included and the risk of a hidden bias (although to a lesser extent) remained.

To significantly reduce the risk of a bias due to the different treatments used, we created the WBRT-30 published in 2013 [14]. In contrast to the previous scores, the cohort of patients used for the WBRT-30 was uniformly treated with WBRT alone using $30 \mathrm{~Gy}$ in 10 fractions. The positive predictive values (PPVs) of the WBRT-30 to identify patients dying $\leq 6$ months and those surviving $\geq 6$ months were quite high (97\% and 96\%), demonstrating a high level of accuracy [14]. These PPVs were higher than for the RPA classification (92\% and 75\%), the GPA classification ( $85 \%$ and $64 \%$ ) and our previous score $(96 \%$ and $73 \%$ ) [11-13]. Therefore, the WBRT-30 could be recommended when aiming to predict death within 6 months or survival for at least 6 months following WBRT.

In order to account for the different biology of tumor entities associated with brain metastases and to further improve the personalization of the treatment for these patients, separate scoring tools for each tumor type are important. Such tools are already available for patients with brain metastasis from SCLC including the original diagnosis-specific graded prognostic assessment (DS-GPA) classifications, the updated diagnosis-specific graded prognostic assessment DS-GPA classification and the Rades-SCLC score. In addition, significant prognostic factors were identified in a cohort of 229 patients with brain metastases from SCLC including performance status, time of appearance of brain metastases, initial response to chemotherapy and RPA-class [15]. In this study, 95\% of the patients received WBRT with $30 \mathrm{~Gy}$ in 10 fractions, which likely led to a significant reduction of hidden selection biases. However, no scoring tool was created from the significant prognostic factors [15]. In the present study, another diagnosis-specific score for patients with brain metastases from SCLC was developed. Considering the high PPVs to correctly identify patients dying within 6 months and patients living for at least 6 months of the (general) WBRT-30 [14] the new diagnosis-specific WBRT-30-SCLC was also created from patients uniformly treated with $30 \mathrm{~Gy}$ in 10 fractions of WBRT alone.

Moreover, the new WBRT-30-SCLC was compared to the three existing tools created for patients irradiated for brain metastases from SCLC with respect to correct identification of patients dying $\leq 6$ months and patients surviving $\geq 6$ months after irradiation. 


\section{Results}

\subsection{Development of the WBRT-30-SCLC}

In the entire cohort, the survival rates at 3,6, 9 and 12 months were $50 \%, 29 \%, 23 \%$ and $17 \%$, respectively. On univariate analysis (Table 1), significant associations with better survival were found for age $\leq 64$ years $(p=0.002)$, Karnofsky performance score (KPS) $>70(p<0.001), 1-3$ cerebral lesions $(p<0.001)$ and no extra-cerebral metastasis at WBRT $(p=0.004)$. A trend towards better survival was found for systemic treatment prior to WBRT $(p=0.07)$ and controlled primary tumor $(p=0.09)$. Gender and interval from diagnosis of SCLC to WBRT $(p=0.71)$ were not significantly associated with survival.

Table 1. Results of the univariate analyses of survival of the factors that may be used to design the the new score developed in patients with brain metastases from small-cell lung cancer receiving whole-brain radiotherapy with $30 \mathrm{~Gy}$ in 10 fractions (WBRT-30-SCLC) including those factors that were significant $(p<0.05)$ or showed a trend $(p<0.10)$.

\begin{tabular}{|c|c|c|c|c|c|}
\hline Factor & $\begin{array}{l}\text { At } 3 \text { Months } \\
\text { (\%) }\end{array}$ & $\begin{array}{l}\text { At } 6 \text { Months } \\
(\%)\end{array}$ & $\begin{array}{l}\text { At } 9 \text { Months } \\
(\%)\end{array}$ & $\begin{array}{l}\text { At } 12 \text { Months } \\
(\%)\end{array}$ & $p$-Value \\
\hline \multicolumn{6}{|l|}{ Age } \\
\hline$\leq 64$ years & 60 & 38 & 33 & 22 & \\
\hline$>64$ years & 38 & 18 & 12 & 12 & 0.002 \\
\hline \multicolumn{6}{|c|}{ Karnofsky Performance Score } \\
\hline$<70$ & 20 & 0 & 0 & 0 & \\
\hline$=70$ & 52 & 34 & 28 & 28 & \\
\hline$>70$ & 76 & 52 & 42 & 28 & $<0.001$ \\
\hline \multicolumn{6}{|c|}{$\begin{array}{c}\text { Systemic treatment prior to } \\
\text { WBRT }\end{array}$} \\
\hline No & 38 & 22 & 20 & 17 & \\
\hline Yes & 55 & 32 & 24 & 17 & 0.07 \\
\hline \multicolumn{6}{|c|}{ Controlled primary tumor } \\
\hline No & 43 & 28 & 21 & 14 & \\
\hline Yes & 55 & 29 & 25 & 21 & 0.09 \\
\hline \multicolumn{6}{|c|}{ Number of brain metastases } \\
\hline $1-3$ & 67 & 54 & 50 & 40 & \\
\hline$\geq 4$ & 42 & 18 & 11 & 7 & $<0.001$ \\
\hline \multicolumn{6}{|c|}{ Extra-cerebral metastasis } \\
\hline No & 58 & 50 & 41 & 39 & \\
\hline Yes & 47 & 22 & 17 & 10 & 0.004 \\
\hline
\end{tabular}

In the Cox regression analysis, age (risk ratio [RR]: 1.66; 95\%-confidence interval [CI]: 1.17-2.35; $p=0.004)$, KPS (RR: 1.91; 95\%-CI: 1.52-2.41; $p<0.001$ ) and number of cerebral lesions (RR: 1.21 ; 95\%-CI: $1.06-1.39 ; p=0.005$ ) were significant, and extra-cerebral metastasis (RR: 1.49; 95\%-CI: 0.99-2.32; $p=0.058)$ was almost significant.

These factors were used to design the WBRT-30-SCLC as described in the Materials and Methods section. Factor scores are shown in Table 2. After adding the factors scores for each patient, patient scores were received that ranged between 6 and 19 points (Figure 1). The 6-month survival rates of the patient scores led to three prognostic groups: 6-11 points $(n=96), 12-14$ points $(n=32)$ and 16-19 points $(n=29)$. The 6-month survival rates of these groups were $6 \%, 44 \%$ and $86 \%(p<0.001$, Figure 2$)$. 
Table 2. Factor scores used for creating the WBRT-30-SCLC.

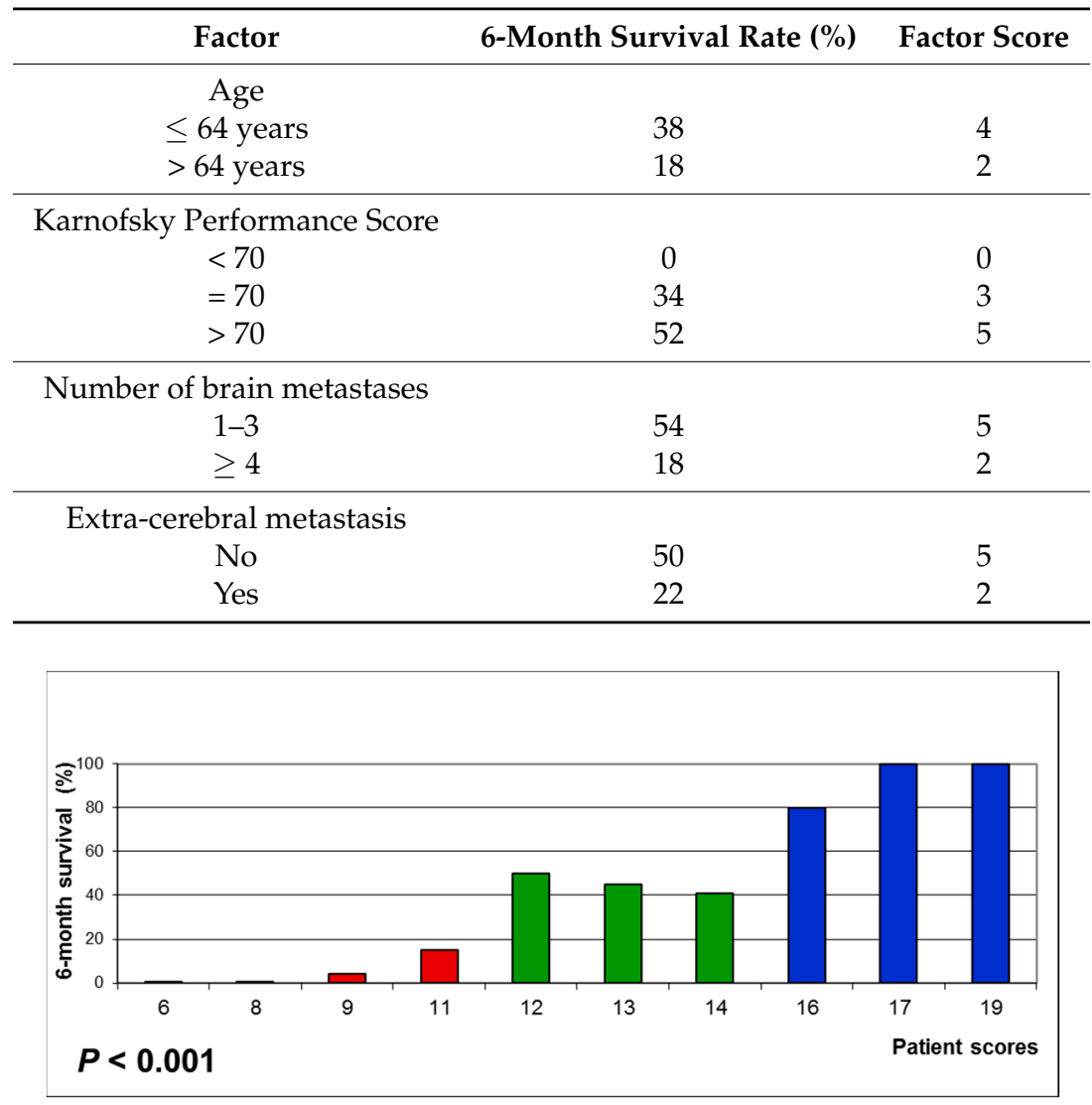

Figure 1. Six-month survival rates of the patient scores used for designing the prognostic groups of the new score developed in patients with brain metastases from small-cell lung cancer receiving whole-brain radiotherapy with $30 \mathrm{~Gy}$ in 10 fractions (WBRT-30-SCLC). A $p$-value of $<0.05$ was considered significant.

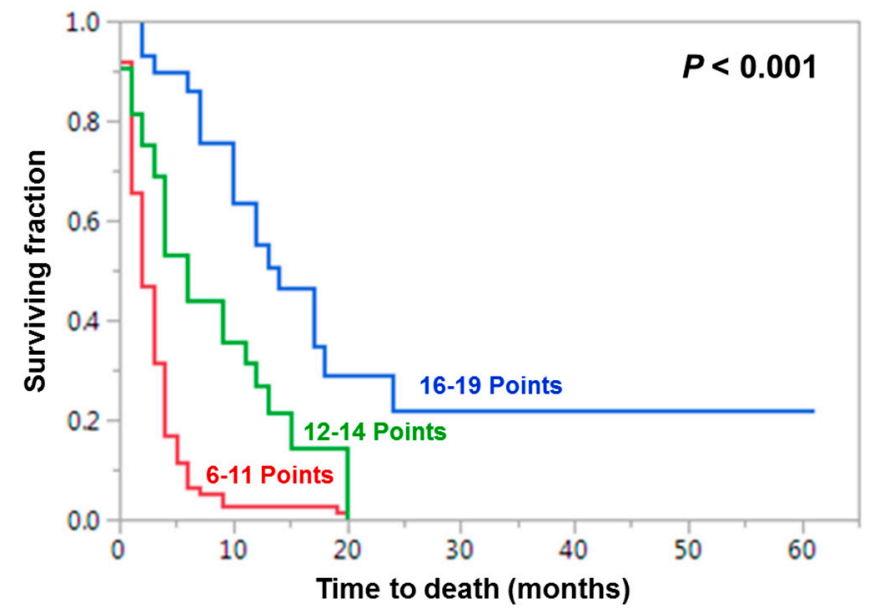

Figure 2. Kaplan-Meier curves of the three prognostic groups of the WBRT-30-SCLC. A $p$-value of $<0.05$ was considered significant.

\subsection{Comparison of Four Disease-Specific Survival Scores for Patients with Brain Metastasis from SCLC}

The prognostic groups of the WBRT-30-SCLC and the other three scores are shown in Table 3. The positive predictive value (PPV) of the least favorable prognostic group (6-11 points) of the new WBRT-30-SCLC to correctly identify patients dying $\leq 6$ months after irradiation was $94 \%$. The corresponding PPVs were $88 \%$ in patients with the least favorable score of $0.0-1.0$ in both the 
original and the updated DS-GPA classifications for SCLC and 100\% in the least favorable group (5-8 points) of our previous score (Rades-SCLC) [16-18]. The PPV of the most favorable group (16-19 points) of the WBRT-30-SCLC to identify patients surviving $\geq 6$ months after irradiation was $86 \%$. The corresponding PPVs were 75\% for a score of 3.0-4.0 in the original DS-GPA, $76 \%$ for a score of 2.5-4.0 in the updated DS-GPA classification, and 100\% in the Rades-SCLC. DS-GPA scores of 3.0-4.0 and $2.5-4.0$ were chosen, since only two patients had a score $>3.0[16,17]$.

Table 3. Prognostic groups of WBRT-30-SCLC, Rades-SCLC and original and updated diagnosis-specific graded prognostic assessment (DS-GPS) classifications [16-18].

\begin{tabular}{|c|c|c|c|c|c|c|c|c|}
\hline \multirow[t]{2}{*}{$\begin{array}{l}\text { ColuPrognostic } \\
\text { Group }\end{array}$} & \multicolumn{2}{|c|}{ WBRT-30-SCLC } & \multicolumn{2}{|c|}{ Rades-SCLC } & \multicolumn{2}{|c|}{ Original DS-GPA } & \multicolumn{2}{|c|}{ Updated DS-GPA } \\
\hline & $\begin{array}{l}\text { Scoring } \\
\text { points }\end{array}$ & $\begin{array}{l}\text { 6-month } \\
\text { Survival }\end{array}$ & $\begin{array}{l}\text { Scoring } \\
\text { points }\end{array}$ & $\begin{array}{l}\text { 6-month } \\
\text { survival }\end{array}$ & $\begin{array}{l}\text { Scoring } \\
\text { points }\end{array}$ & $\begin{array}{l}\text { 6-month } \\
\text { survival }\end{array}$ & $\begin{array}{l}\text { Scoring } \\
\text { points }\end{array}$ & $\begin{array}{l}\text { 6-month } \\
\text { survival }\end{array}$ \\
\hline Poor prognosis & $6-11$ & $6 \%(6 / 96)$ & $5-8$ & $0 \%(0 / 59)$ & $0.0-1.0$ & $\begin{array}{c}12 \% \\
(12 / 103)\end{array}$ & $0.0-1.0$ & $12 \%(12 / 103)$ \\
\hline $\begin{array}{c}\text { Intermediate } \\
\text { prognosis }\end{array}$ & $12-14$ & $44 \%(14 / 32)$ & $9-12$ & $40 \%(35 / 88)$ & $1.5-2.5$ & $59 \%(27 / 46)$ & $1.5-2.0$ & $54 \%(20 / 37)$ \\
\hline $\begin{array}{l}\text { Favorable } \\
\text { prognosis }\end{array}$ & $16-19$ & $86 \%(25 / 29)$ & 15 & $100 \%(10 / 10)$ & $\geq 3.0$ & $75 \%(6 / 8)$ & $\geq 2.5$ & $76 \%(13 / 17)$ \\
\hline
\end{tabular}

For the WBRT-30-SCLC, the differences between the 6-11 points (poor prognoses) and the $12-14$ points (intermediate prognoses) groups $(p<0.001)$ and between the $12-14$ points and the 16-19 points (favorable prognoses) groups $(p=0.037)$ were significant. Also for our previous Rades-SCLC score, the differences between the 5-8 points (poor prognosis) and the 9-12 points (intermediate prognosis) groups $(p<0.001$ ) and between the $9-12$ points and the 15 points (favorable prognosis) groups $(p=0.008)$ were significant. For the both the original and the updated DS-GPA scores, the difference between $0.0-1.0$ and 1.5-2.0 was significant $(p<0.001$ and $p<0.001$, respectively), but the differences between 1.5-2.0 and 3.0-4.0 in the original DS-GPA classification $(p=0.59)$ and between 1.5-2.0 and 2.5-4.0 in the updated DS-GPA classification $(p=0.33)$ were not $[16,17]$.

Thus, of the four compared disease-specific tools, the Rades-SCLC appeared to be the most accurate in identifying both patients dying $\leq 6$ months and patients surviving $\geq 6$ months after irradiation, followed by the new WBRT-30-SCLC and the two DS-GPA classifications [16-18].

\section{Discussion}

If a patient has developed brain metastases, the situation is palliative and personalized treatment regimens are required to optimally meet an individual patient's needs $[1,19,20]$. If the decision has been made that the patient should receive WBRT, it is important to select the appropriate doe-fractionation regimen to avoid under-or overtreatment. Patients with very favorable survival prognoses can benefit from longer-course WBRT with total doses $>30 \mathrm{~Gy}$. A previous study compared $40 \mathrm{~Gy}$ in 20 fractions to $30 \mathrm{~Gy}$ in 10 fractions in 186 patients with favorable survival prognoses [10]. The 1-year intracerebral control rates were $44 \%$ and $28 \%$ ( $p=0.047$ on multivariate analysis), and the 1-year survival rates $61 \%$ and $50 \%$ ( $p=0.008$ on multivariate analysis). Moreover, doses per fraction $>3.0-3.5$ Gy were suggested to result in greater neuro-cognitive deficits than lower doses per fraction $[5,6]$. Since the risk of developing a decline in neuro-cognitive function is positively correlated with lifetime, patients with more favorable survival prognoses should receive lower doses per fraction. The risk of a WBRT-induced decline in neuro-cognitive function can be further reduced with hippocampal sparing $[7,8]$. In a previous phase 2 trial, decline in neuro-cognitive function at 4 months following WBRT (30 Gy in 10 fractions) was $7 \%$ in patients receiving hippocampal sparing versus $30 \%$ in a historical control group $(p<0.001)$ [7]. In an additional study of patients with SCLC receiving prophylactic or therapeutic WBRT, 59 patients experienced new brain metastases and 20 patients a progression of treated lesions [8]. Of this series, only 3 patients $(5 \%)$ and 1 patient $(5 \%)$, respectively, had new or progressive lesions in the hippocampal avoidance region. Therefore, hippocampal sparing appears to be a reasonable option 
for patients with brain metastasis from SCLC. Another option to reduce neuro-cognitive deficits is the administration of memantine [9]. In a randomized, placebo-controlled trial of 554 patients receiving WBRT plus/minus memantine, the interval to neuro-cognitive decline was significantly longer in the memantine group $(p=0.01)$, and the probability of neuro-cognitive dysfunction at 24 weeks was $54 \%$ with and $65 \%$ without memantine [9]. On the other hand, for patients with a poor expected survival, WBRT with 20 Gy in 5 fractions is considered more appropriate, since it is similarly effective for intracerebral control and survival as longer-course WBRT schedules and is not associated with increased acute toxicity [1,4]. Selected patients may also be considered for best supportive care (BSC) including corticosteroids. In a randomized trial of patients with brain metastases from non-small cell lung cancer and a very poor survival prognosis, treatment with BSC and dexamethasone was not inferior to BSC and dexamethasone plus short-course WBRT with 20 Gy in 5 fractions [21,22].

It is very important to be able to judge a patient's survival prognosis before assigning a WBRT schedule. To support the treating physicians, several prognostic tools were created [11-14].

In order to provide optimal personalization of the treatment including the most appropriate WBRT schedule, diagnosis-specific tools would be desirable taking into account the differences of the various primary tumor types with respect to biological behavior and prognoses. Diagnosis-specific classifications for brain metastasis from SCLC already exist, including an original and an updated DS-GPA and our previous score including two different WBRT regimens [16-18]. Since the PPVs of the WBRT-30 were quite promising, we decided to create a diagnosis-specific WBRT-30 particularly for patients with SCLC, the WBRT-30-SCLC.

This new tool included three prognostic groups with significantly different 6-month survival probabilities. When compared to the original and the updated DS-GPS for SCLC, the PPV of the WBRT-30-SCLC to correctly identify patients dying $\leq 6$ months following irradiation was slightly higher $(94 \%$ vs. $88 \%$ ). However, it was slightly lower than with the previous Rades-SCLC score $(94 \%$ vs. $100 \%)$. When aiming to identify patients surviving $\geq 6$ months, the PPV of the WBRT-30-SCLC was $11 \%$ and $10 \%$ higher than with the DS-GPA classifications ( $86 \%$ vs. $75 \%$ and $76 \%$ ) but was $14 \%$ lower than with the Rades-SCLC ( $86 \%$ vs. $100 \%$ ).

Moreover, the differences in 6-month survival between the poor-prognosis and the intermediate-prognosis group and between the intermediate-prognosis and the favorable-prognosis group of the WBRT-30-SCLC were significant. So were the differences when using the Rades-SCLC [18]. In contrast, when applying both DS-GPA classifications, only the difference between the poor-prognosis and the intermediate-prognosis group was significant $[16,17]$. Thus, the WBRT-30-SCLC appeared more accurate than the original and the updated DS-GPA classifications in identifying patients surviving $\geq 6$ months. Such superiority was already shown for the general WBRT-30 when compared to the general GPA classification (PPV 96\% vs. 64\%) [14]. The general WBRT-30 was also more accurate in identifying patients surviving $\geq 6$ months than the general Rades-score developed in patients receiving different WBRT-schedules (PPV 95\% vs. 73\%) [13]. Surprisingly the WBRT-30-SCLC appeared to be less accurate than the previous Rades-SCLC, although patients included in the WBRT-30-SCLC received a more homogeneous treatment and the data, therefore, had a lower risk of being influenced by a selection bias. This finding supports the idea of different behavior of various solid tumors such as SCLC.

The WBRT-30-SCLC needs to be validated in a separate cohort of patients in the future because advances in systemic therapies, especially the development immuno-therapies that can cross the blood-brain-barrier will have an impact on the survival of patients with brain metastases from lung cancer. Promising results were reported for immune checkpoint inhibitors or alk inhibitors in patients with brain metastases from non-small cell lung cancer [23-26]. Moreover, a phase 2 study of maintenance pembrolizumab in 45 patients with extensive disease SCLC, of whom $22 \%$ had treated brain metastases, suggested that a subset of these patients could benefit from this treatment [27]. 


\section{Materials and Methods}

In order to create a new disease-specific survival score (WBRT-30-SCLC) for patients with brain metastasis from SCLC, eight factors were evaluated for potential impact on survival in a retrospective cohort of 157 patients receiving WBRT alone with 30 Gy in 10 fractions between 1998 and 2017 (Table 4). The study was approved by the ethics committee of the University of Lübeck (reference: 19-003A). Univariate analyses of survival were performed using the Kaplan-Meier method and the log-rank test. Significant factors $(p<0.05)$ were included in a Cox regression analysis. Factors achieving significance $(p<0.05)$ or almost significance $(p<0.06)$ in the Cox regression analysis were used for the WBRT-30-SCLC. Factor scores were obtained from the 6-month survival rates divided by 10 and patient scores by addition of the factor scores for each patient. The patient scores were used for designing the prognostic groups.

Table 4. Distribution of the potential prognostic factors evaluated for potential inclusion in the WBRT-30-SCLC.

\begin{tabular}{|c|c|}
\hline Factor & N Patients (\%) \\
\hline \multicolumn{2}{|l|}{ Age } \\
\hline$\leq 64$ years & $81(52)$ \\
\hline$>64$ years & $76(48)$ \\
\hline \multicolumn{2}{|l|}{ Gender } \\
\hline Female & $60(38)$ \\
\hline Male & $97(62)$ \\
\hline \multicolumn{2}{|c|}{ Karnofsky Performance Score } \\
\hline$<70$ & $61(39)$ \\
\hline$=70$ & $29(18)$ \\
\hline$>70$ & $67(43)$ \\
\hline \multicolumn{2}{|c|}{$\begin{array}{l}\text { Interval from diagnosis of } \\
\text { SCLC to WBRT }\end{array}$} \\
\hline$\leq 2$ months & $80(51)$ \\
\hline$>2$ months & $77(49)$ \\
\hline \multicolumn{2}{|c|}{ Systemic treatment prior to WBRT } \\
\hline No & $50(32)$ \\
\hline Yes & $107(68)$ \\
\hline \multicolumn{2}{|c|}{ Controlled primary tumor } \\
\hline No & $74(47)$ \\
\hline Yes & $83(53)$ \\
\hline \multicolumn{2}{|c|}{ Number of brain metastases } \\
\hline $1-3$ & $46(29)$ \\
\hline$\geq 4$ & $111(71)$ \\
\hline \multicolumn{2}{|c|}{ Extra-cerebral metastasis } \\
\hline No & $38(24)$ \\
\hline Yes & $119(76)$ \\
\hline
\end{tabular}

The WBRT-30-SCLC and three other disease-specific scores for SCLC were compared with respect to positive predictive values (PPV) for correctly predicting death $\leq 6$ months and survival $\geq 6$ months after irradiation [16-18]. The other scores included the original and the updated diagnosis-specific graded prognostic assessment (DS-GPA) classifications for SCLC (Table 5) and our previous score (Rades-SCLC) created in a cohort of patients receiving WBRT with $20 \mathrm{~Gy}$ in 5 fractions or 30 Gy in 10 fractions (Table 6). In addition, the discrimination between the prognostic groups was analyzed for each of the four scoring systems using the Chi-square test. 
Table 5. Diagnosis-specific graded prognostic assessment (DS-GPA) classification for patients with brain metastasis from SCLC $[16,17]$.

\begin{tabular}{cccc}
\hline \multirow{2}{*}{ Colu Factor } & \multicolumn{3}{c}{ GPA Scoring Criteria } \\
\cline { 2 - 4 } & $\mathbf{0}$ & $\mathbf{0 . 5}$ & $\mathbf{1 . 0}$ \\
\hline Age (years) & $>60$ & $50-60$ & $<50$ \\
Karnofsky Performance Score & $<70$ & $70-80$ & $90-100$ \\
Extra-cerebral metastasis & present & - & absent \\
Number of brain metastases & $>3$ & $2-3$ & 1 \\
\hline
\end{tabular}

Prognostic groups of the original DS-GPA: 0.0-1.0, 1.5-2.5, 3.0, 3.5-4.0, higher scores $=$ better prognoses [16]. Prognostic groups of the updated DS-GPA: 0.0-1.0, 1.5-2.0, 2.5-3.0, 3.5-4.0, higher scores = better prognoses [17].

Table 6. Scoring points of the previous Rades-SCLC score [18].

\begin{tabular}{ccc}
\hline Factor & 6-Month Survival Rate (\%) & Factor Score \\
\hline Karnofsky Performance Score & 5 & \\
$<70$ & 51 & 5 \\
$\geq 70$ & & \\
\hline Number of brain metastases & 54 & 5 \\
$1-3$ & 18 & 2 \\
$\geq 4$ & & \\
\hline Extra-cerebral metastasis & 50 & 5 \\
No & 22 & 2 \\
\hline Yes
\end{tabular}

Prognostic groups of the Rades-SCLC: 5-8 points, 9-12 points, 15 points, higher scores = better prognoses [17].

\section{Conclusions}

A new diagnosis-specific tool (WBRT-30-SCLC) was created to estimate the remaining lifespan of patients irradiated for brain metastasis from SCLC. The WBRT-30-SCLC appeared to be superior to the original and the updated GPA classifications, particularly for identifying patients surviving $\geq 6$ months. The WBRT-30-SCLC and both DS-GPA classifications appeared less accurate than the Rades-SCLC. Thus, the Rades-SCLC is the preferable tool when physicians aim to predict the survival prognosis of a patient with brain metastasis from SCLC that is planned to be treated with WBRT.

Author Contributions: Conceptualization, D.R., H.C.H., S.J. and S.E.S.; methodology, D.R., H.C.H., S.J. and S.E.S.; validation, D.R., H.C.H., S.J. and S.E.S.; formal analysis, D.R. and S.E.S.; investigation, D.R., H.C.H., S.J. and S.E.S.; resources, D.R., H.C.H., S.J. and S.E.S.; data curation, D.R. and S.E.S.; Writing-Original draft preparation, D.R. and S.E.S.; Writing—Review and Editing, D.R., H.C.H., S.J. and S.E.S.; visualization, D.R., H.C.H., S.J. and S.E.S.

Funding: This research received no external funding.

Conflicts of Interest: The authors declare no conflict of interest.

\section{References}

1. Tsao, M.N.; Rades, D.; Wirth, A.; Lo, S.S.; Danielson, B.L.; Gaspar, L.E.; Sperduto, P.W.; Vogelbaum, M.A.; Radawski, J.D.; Wang, J.Z.; et al. Radiotherapeutic and surgical management for newly diagnosed brain metastasis(es): An American Society for Radiation Oncology evidence-based guideline. Pract. Radiat. Oncol. 2012, 2, 210-225. [CrossRef] [PubMed]

2. Yamamoto, M.; Serizawa, T.; Shuto, T.; Akabane, A.; Higuchi, Y.; Kawagishi, J.; Yamanaka, K.; Sato, Y.; Jokura, H.; Yomo, S.; et al. Stereotactic radiosurgery for patients with multiple brain metastases (JLGK0901): A multi-institutional prospective observational study. Lancet Oncol. 2014, 15, 387-395. [CrossRef]

3. Schild, S.E.; Sio, T.T.; Daniels, T.B.; Chun, S.G.; Rades, D. Prophylactic cranial irradiation for extensive small-cell lung cancer. J. Oncol. Pract. 2017, 13, 732-738. [CrossRef] [PubMed] 
4. Rades, D.; Kieckebusch, S.; Lohynska, R.; Veninga, T.; Stalpers, L.J.; Dunst, J.; Schild, S.E. Reduction of overall treatment time in patients irradiated for more than three brain metastases. Int J. Radiat. Oncol. Biol. Phys. 2007, 69, 1509-1513. [CrossRef] [PubMed]

5. DeAngelis, L.M.; Delattre, J.Y.; Posner, J.B. Radiation-induced dementia in patients cured of brain metastases. Neurology 1989, 39, 789-796. [CrossRef] [PubMed]

6. Brown, P.D.; Ahluwalia, S.; Khan, O.H.; Asher, A.L.; Wefel, J.S.; Gondi, V. Whole-brain radiotherapy for brain metastases: Evolution or revolution? J. Clin. Oncol. 2018, 36, 483-491. [CrossRef] [PubMed]

7. Gondi, V.; Pugh, S.L.; Tome, W.A.; Caine, C.; Corn, B.; Kanner, A.; Rowley, H.; Kundapur, V.; DeNittis, A.; Greenspoon, J.N.; et al. Preservation of memory with conformal avoidance of the hippocampal neural stem-cell compartment during whole-brain radiotherapy for brain metastases (RTOG 0933): A phase II multi-institutional trial. J. Clin. Oncol. 2014, 32, 3810-3816. [CrossRef]

8. Kundapur, V.; Ellchuk, T.; Ahmed, S.; Gondi, V. Risk of hippocampal metastases in small cell lung cancer patients at presentation and after cranial irradiation: A safety profile study for hippocampal sparing during prophylactic or therapeutic cranial irradiation. Int. J. Radiat. Oncol. Biol. Phys. 2015, 91, 781-786. [CrossRef]

9. Brown, P.D.; Pugh, S.; Laack, N.N.; Wefel, J.S.; Khuntia, D.; Meyers, C.; Choucair, A.; Fox, S.; Suh, J.H.; Roberge, D.; et al. Radiation Therapy Oncology Group (RTOG): Memantine for the prevention of cognitive dysfunction in patients receiving whole-brain radiotherapy: A randomized, double-blind, placebo-controlled trial. Neuro Oncol. 2013, 15, 1429-1437. [CrossRef]

10. Rades, D.; Panzner, A.; Dziggel, L.; Haatanen, T.; Lohynska, R.; Schild, S.E. Dose-escalation of whole-brain radiotherapy for brain metastasis in patients with a favorable survival prognosis. Cancer 2012, 118, 3852-3859. [CrossRef]

11. Gaspar, L.; Scott, C.; Rotman, M.; Asbell, S.; Phillips, T.; Wasserman, T.; McKenna, W.G.; Byhardt, R. Recursive partitioning analysis (RPA) of prognostic factors in three Radiation Therapy Oncology Group (RTOG) brain metastases trials. Int. J. Radiat. Oncol. Biol. Phys. 1997, 37, 745-751. [CrossRef]

12. Sperduto, P.W.; Berkey, B.; Gaspar, L.E.; Mehta, M.; Curran, W. A new prognostic index and comparison to three other indices for patients with brain metastases: An analysis of 1960 patients in the RTOG database. Int. J. Radiat. Oncol. Biol. Phys. 2008, 70, 510-514. [CrossRef] [PubMed]

13. Rades, D.; Dunst, J.; Schild, S.E. A new scoring system to predicting the survival of patients treated with whole-brain radiotherapy for brain metastases. Strahlenther. Onkol. 2008, 184, 251-255. [CrossRef] [PubMed]

14. Rades, D.; Dziggel, L.; Nagy, V.; Segedin, B.; Lohynska, R.; Veninga, T.; Khoa, M.T.; Trang, N.T.; Schild, S.E. A new survival score for patients with brain metastases who received whole-brain radiotherapy (WBRT) alone. Radiother. Oncol. 2013, 108, 123-127. [CrossRef] [PubMed]

15. Bernhardt, D.; Adeberg, S.; Bozorgmehr, F.; Opfermann, N.; Hoerner-Rieber, J.; König, L.; Kappes, J.; Thomas, M.; Herth, F.; Heußel, C.P.; et al. Outcome and prognostic factors in patients with brain metastases from small-cell lung cancer treated with whole brain radiotherapy. J. Neurooncol. 2017, 134, $205-212$. [CrossRef] [PubMed]

16. Sperduto, P.W.; Chao, S.T.; Sneed, P.K.; Luo, X.; Suh, J.; Roberge, D.; Bhatt, A.; Jensen, A.W.; Brown, P.D.; Shih, H.; et al. Diagnosis-specific prognostic factors, indexes, and treatment outcomes for patients with newly diagnosed brain metastases: A multi-institutional analysis of 4,259 patients. Int. J. Radiat. Oncol. Biol. Phys. 2010, 77, 655-661. [CrossRef]

17. Sperduto, P.W.; Kased, N.; Roberge, D.; Xu, Z.; Shanley, R.; Luo, X.; Sneed, P.K.; Chao, S.T.; Weil, R.J.; Suh, J.; et al. Summary report on the graded prognostic assessment: An accurate and facile diagnosis-specific tool to estimate survival for patients with brain metastases. J. Clin. Oncol. 2012, 30, 419-425. [CrossRef]

18. Rades, D.; Dziggel, L.; Segedin, B.; Oblak, I.; Nagy, V.; Marita, A.; Schild, S.E. The first survival score for patients with brain metastases from small cell lung cancer (SCLC). Clin. Neurol. Neurosurg. 2013, 115, 2029-2032. [CrossRef]

19. Wong, J.; Hird, A.; Zhang, L.; Tsao, M.; Sinclair, E.; Barnes, E.; Danjoux, C.; Chow, E. Symptoms and quality of life in cancer patients with brain metastases following palliative radiotherapy. Int. J. Radiat. Oncol. Biol. Phys. 2009, 75, 1125-1131. [CrossRef]

20. van Oorschot, B.; Beckmann, G.; Schulze, W.; Rades, D.; Feyer, P. Radiotherapeutic options for symptom control in breast cancer. Breast Care (Basel) 2011, 6, 14-19. [CrossRef] 
21. Mulvenna, P.; Nankivell, M.; Barton, R.; Faivre-Finn, C.; Wilson, P.; McColl, E.; Moore, B.; Brisbane, I.; Ardron, D.; Holt, T.; et al. Dexamethasone and supportive care with or without whole brain radiotherapy in treating patients with non-small cell lung cancer with brain metastases unsuitable for resection or stereotactic radiotherapy (QUARTZ): Results from a phase 3, non-inferiority, randomised trial. Lancet 2016, 388, 2004-2014. [CrossRef] [PubMed]

22. Agarwal, J.P.; Chakraborty, S.; Laskar, S.G.; Mummudi, N.; Patil, V.M.; Upasani, M.; Prabhash, K.; Noronha, V.; Joshi, A.; Purandare, N.; et al. Applying the QUARTZ Trial Results in Clinical Practice: Development of a Prognostic Model Predicting Poor Outcomes for Non-small Cell Lung Cancers with Brain Metastases. Clin. Oncol. (R. Coll. Radiol.) 2018, 30, 382-390. [CrossRef] [PubMed]

23. Thapa, B.; Lauko, A.; Desai, K.; Venur, V.A.; Ahluwalia, M.S. Novel systemic treatments for brain metastases from lung cancer. Curr. Treat. Opt. Neurol. 2018, 20, 48. [CrossRef] [PubMed]

24. Kim, R.; Keam, B.; Kim, S.; Kim, M.; Kim, S.H.; Kim, J.W.; Kim, Y.J.; Kim, T.M.; Jeon, Y.K.; Kim, D.W.; et al. Differences in tumor microenvironments between primary lung tumors and brain metastases in lung cancer patients: Therapeutic implications for immune checkpoint inhibitors. BMC Cancer 2019, 19, 19. [CrossRef] [PubMed]

25. Melosky, B.; Cheema, P.; Agulnik, J.; Albadine, R.; Bebb, D.G.; Blais, N.; Burkes, R.; Butts, C.; Card, P.B.; Chan, A.M.Y.; et al. Canadian perspectives: Update on inhibition of ALK-positive tumours in advanced non-small-cell lung cancer. Curr. Oncol. 2018, 25, 317-328. [CrossRef] [PubMed]

26. Kamath, S.D.; Kumthekar, P.U. Immune checkpoint inhibitors for the treatment of central nervous system (CNS) metastatic disease. Front. Oncol. 2018, 8, 414. [CrossRef] [PubMed]

27. Gadgeel, S.M.; Pennell, N.A.; Fidler, M.J.; Halmos, B.; Bonomi, P.; Stevenson, J.; Schneider, B.; Sukari, A.; Ventimiglia, J.; Chen, W.; et al. Phase II Study of Maintenance Pembrolizumab in Patients with Extensive-Stage Small Cell Lung Cancer (SCLC). J. Thorac. Oncol. 2018, 13, 1393-1399. [CrossRef]

(C) 2019 by the authors. Licensee MDPI, Basel, Switzerland. This article is an open access article distributed under the terms and conditions of the Creative Commons Attribution (CC BY) license (http:/ / creativecommons.org/licenses/by/4.0/). 